\title{
METODOLOGIAS DE DESNUDAMENTO PARCIAL DE OÓCITOS BOVINOS MATURADOS E SUBMETIDOS À VITRIFICAÇÃO
}

\section{(Methods for partial denudment of maturated bovine oocytes submitted to vitrification)}

\author{
MEZZALIRA, A. ${ }^{1}$; CUCCO, D.C. ${ }^{1}$; BUNN, S. ${ }^{1}$; CRUZ, F.B. ${ }^{1}$; WERLICH, D.E. ${ }^{1}$; VIEIRA, A.D. ${ }^{2}$; SANTOS, R.M. ${ }^{3}$ \\ 'Laboratório de Reprodução Animal Prof. Assis Roberto de Bem, Centro de Ciências Agroveterinárias, \\ Universidade do Estado de Santa Catarina - CAV/UDESC. Av. Luiz de Camões 2090, Lages-SC-Brasil. \\ Fone 492212213 E-mail autor: mezzalira@cav.udesc.br; \\ ${ }^{2}$ Médico Veterinário , Doutorando UFRGS - Porto Alegre RS; \\ ${ }^{3}$ Médico Veterinário autônomo - Santiago RS.
}

RESUMO - Diferentes metodologias de desnudamento parcial de oócitos bovinos maturados foram avaliadas na produção in vitro de embriões e na vitrificação, em três experimentos. No primeiro avaliou-se o efeito do desnudamento parcial realizado por sucessivas pipetagens. No segundo, comparou-se o desnudamento através de sucessivas pipetagens, com o realizado pela enzima hialuronidase e no terceiro, avaliou-se a influência das duas metodologias na vitrificação de oócitos. Os oócitos foram submetidos aos tratamentos após 22 horas de maturação em meio TCM 199. Para a vitrificação, foram expostos por 30 segundos a uma solução de equilíbrio e 20 segundos a uma solução de vitrificação (20\%EG + $20 \%$ Dimitilsufoxido (DMSO) + 0,3MSAC), envasados em palhetas abertas e estiradas (OPS) e mergulhados em $\mathrm{N}_{2}$ líquido. $\mathrm{O}$ reaquecimento foi realizado com exposição a concentrações decrescentes de sacarose. Os oócitos de todos os tratamentos foram submetidos a duas horas adicionais de maturação, seguida da fecundação e os possíveis zigotos cultivados em meio SOFaaci. No experimento I foi observado um decréscimo de $28,7 \%$ para $20,5 \%$ na taxa de blastocistos com o emprego do desnudamento $(P<0,05)$. Os métodos de desnudamento (sucessivas pipetagens ou enzima hialuronidase) proporcionaram semelhante taxa de blastocistos após cultivo (17,7\% e 21,7\% - Experimento II), bem como após a vitrificação (6,4\% e 8,9\% - Experimento III). Todavia, a hialuronidase determinou um desnudamento parcial mais homogêneo. Conclui-se que a hialuronidase pode substituir as sucessivas pipetagens no desnudamento parcial de oócitos, com idêntica viabilidade e maior praticidade.

Palavras-chave: Oócitos; Bovino; Desnudamento; Vitrificação, Células cumulus.

ABSTRACT - Different methods of partial denudation of maturated bovine oocytes were evaluated for in vitro embryo production and vitrification procedures, in three experiments. First the effect of partial denudation by successive pipetting was evaluated. In the second experiment, the denudation by pipetting was compared with the use of hyaluronidase, and finally, the effect of both methods was evaluated in regard to the vitrification of oocytes. Oocytes were submitted to treatments after 22 hours of maturation in TCM 199 medium. For the vitrification, they were firstly exposed for 30 seconds to an equilibrium solution and for 20 seconds to a vitrification solution (20\% EG + $20 \%$ DMSO + $0.3 \mathrm{M}$ SUC), loaded in open pulled straws (OPS) and plunged into liquid nitrogen. The rewarming of the oocytes suspensions was carried out by plunged them in decreasing sucrose concentrations. Oocytes of all treatments were submitted to an additional 2 hours maturation period, followed by fertilization. Presumptive zygotes were cultured in SOFaaci medium. In the first experiment the denudation resulted in a decreased blastocyst rate $(28.7 \%$ to $20.5 \%-P<0.05)$. Both denudation methods (pipetting or hyaluronidase) provided similar blastocyst rate after culture $(17.7 \%$ and $21.7 \%$ - Experiment II), as well as after vitrification (6.4\% and $8.9 \%$ - Experiment III). Though, partial denudation was more homogeneous with the effect of hyaluronidase We concluded that hyaluronidase can replace the use of pipette in the partial denudation of bovine oocytes, with identical viability, being easier to be conduced.

Key-words: Oocyte; Bovine; Denudment; Vitrification, Cumulus cells. 


\section{Introdução}

A técnica de criopreservação de embriões bovinos já esta bem estabelecida, proporcionando resultados próximos aos obtidos após transferência de embriões frescos. Entretanto, na criopreservação de oócitos bovinos os resultados ainda são pobres em função da maior sensibilidade dos componentes do citoesqueleto, da zona pelúcida e dos fusos meióticos, tanto ao resfriamento quanto à ação dos crioprotetores (PARKS e RUFFINING, 1992). Segundo LIM et al. (1992), maior sobrevivência, taxa de clivagem e desenvolvimento são observadas com oócitos em maturação ou maturados, em relação aos imaturos, bem como em oócitos criopreservados no estágio de pró-núcleo, quando comparados aos maturados. Isto evidencia que a sensibilidade à criopreservação de oócitos é dependente do estágio de maturação dos mesmos, sendo que os maturados proporcionam melhores resultados. Entretanto, para a criopreservação destes oócitos, principalmente com o processo de vitrificação, existe a necessidade da remoção parcial das células do cumulus oophorus, já que a expansão destas, determinada pela maturação, dificulta o manuseio e a permeação dos crioprotetores. Sabe-se que algumas camadas de células do cumulus são necessárias para uma adequada fecundação dos oócitos bovinos, existindo evidências de que as células do cumulus estão envolvidas na interação entre os gametas masculino e feminino, guiando o espermatozóide em direção ao oócito, induzindo a capacitação e a reação do acrossoma, mantendo a motilidade e viabilidade espermática, além de prevenir o endurecimento precoce da zona pelúcida e acentuar a penetração espermática (FATEHI et al., 2002). Desta forma, torna-se oportuno determinar as conseqüências do desnudamento parcial na posterior viabilidade dos oócitos maturados, bem como avaliar alternativas que busquem minimizar seus efeitos negativos e assim aumentar a eficiência da criopreservação.

O objetivo deste estudo foi avaliar o desenvolvimento embrionário in vitro de oócitos bovinos submetidos a duas metodologias de desnudamento parcial, associados ou não à vitrificação.

\section{Materiais e Métodos}

O estudo foi conduzido em três experimentos, realizados no Laboratório de Reprodução Animal do Centro de Ciências Agroveterinárias, em Lages, SC. Salvo onde indicado, os reagentes químicos utilizados foram adquiridos da Sigma (Sigma Chemical CO-St. Louis, MO, USA).

Obtenção dos Oócitos: Ovários bovinos obtidos em frigoríficos da região foram transportados em solução salina tamponada com fosfato (PBS) à temperatura aproximada de $30^{\circ} \mathrm{C}$. Os oócitos foram aspirados, através de bomba de vácuo, de folículos com diâmetro de 2 a $8 \mathrm{~mm}$, utilizando-se uma agulha 19G, acoplada a um tubo com capacidade de $15 \mathrm{~mL}$. Após a punção efetuou-se a procura e seleção dos oócitos em placas de Petri $100 \times 15$ mm (Falcon; 1012), no próprio líquido folicular.

Maturação dos Oócitos: Os oócitos foram submetidos a três banhos em meio TCM - 199 ((Gibco BRL, Paisley, NK) tamponado com Hepes e divididos aleatoriamente em grupos de $20 \mathrm{em}$ placas de quatro poços (Nunc S/A-

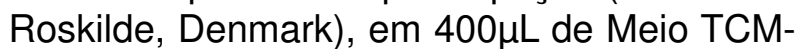
199 sais de Earle. Ao meio era adicionado $26,2 \mathrm{mM}$ de $\mathrm{NaHCO}_{3}, 25 \mathrm{mM}$ de Hepes, $0,2 \mathrm{mM}$ de piruvato de sódio com $0,01 \mathrm{UI}$ de $\mathrm{FSH} / \mathrm{mL}$ (Folltropin $^{\mathrm{TM}}$ - Bioniche, Canada), 0,5 $\mu \mathrm{g} / \mathrm{mL}$ de LH (Lutropin ${ }^{\mathrm{TM}}$ - Bioniche, Canada) e 10\% de soro de égua em estro (SEE). Foram mantidos em estufa de cultivo à $39^{\circ} \mathrm{C}$ (Haeraeus Instruments $\mathrm{GmbH}$, Germany), com atmosfera de $5 \%$ de $\mathrm{CO}_{2}$ e $95 \%$ de umidade relativa.

No experimento I, conduzido em 14 repetições, foram utilizados 809 oócitos em dois grupos, sendo um controle $(n=439)$ e um desnudado por sucessivas pipetagens $(n=370)$. Com 22 horas de maturação, um grupo era

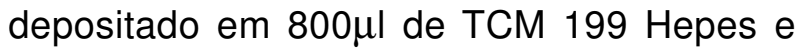
submetidos ao desnudamento parcial por sucessivas pipetagens, com um pipetador manual calibrado em $400 \mu \mathrm{L}$. A cada 5 ou 6 pipetagens os oócitos que apresentavam adequado desnudamento ( 5 ou 6 camadas de células) eram retirados, repetindo-se o 
processo até que todos os oócitos tivessem um adequado desnudamento. Durante este período um grupo controle permanecia no meio de maturação.

O experimento II foi conduzido em 8 repetições, sendo utilizados 451 oócitos, divididos em três grupos experimentais, sendo um controle $(n=153)$, um desnudado com o auxílio de pipetador $(n=149)$ e outro desnudado pela exposição por dois minutos à enzima hialuronidase (Sigma H-2251) na concentração de $0,5 \mathrm{UI} / \mu \mathrm{L}(\mathrm{n}=149)$. Logo após os oócitos eram submetidos a 3 banhos em TCM-Hepes e duas horas adicionais de maturação.

No experimento III, conduzido em 8 repetições, foram utilizados 327 oócitos, sendo 118 desnudados com o auxílio de pipetador e 117 desnudados pela exposição por dois minutos à enzima hialuronidase na concentração de $0,5 \mathrm{UI} / \mu \mathrm{L}$ e a seguir todos foram vitrificados. Para a vitrificação, os oócitos foram expostos por 30 segundos a uma solução composta por $10 \%$ de Etileno Glicol (EG) + 10\% de Dimetil Sulfóxido (DMSO) em TCM-Hepes com $20 \%$ de SEE. Em seguida, foram transferidos a uma solução de vitrificação composta por $20 \%$ de $E G+20 \%$ de DMSO + $0,30 \mathrm{M}$ de sacarose em meio TCM-Hepes com $20 \%$ de SEE, por 20 segundos. Neste período foram envasados em palhetas abertas e estiradas (OPS) e a seguir mergulhados no nitrogênio líquido, num ângulo de 45 graus. No reaquecimento cada OPS foi exposta ao ar (sala climatizada a $25^{\circ} \mathrm{C}$ ) por quatro segundos, sendo em seguida mergulhada em uma solução de $0,30 \mathrm{M}$ de sacarose, em TCM-Hepes, acrescido de $10 \%$ de SEE. Os oócitos permaneceram nesta solução por 5 minutos, quando foram transferidos para uma solução de $0,15 \mathrm{M}$ de sacarose por mais 5 minutos, antes de serem depositados em TCM-Hepes com $10 \%$ de SEE. Como controle, 92 oócitos foram maturados, sendo em seguida fecundados e cultivados até o estágio de blastocisto.

Para a fecundação, os oócitos foram depositados em $400 \mu$ l de meio Talp-Fert, adicionado de $30 \mu \mathrm{g} / \mathrm{ml}$ de heparina, $30 \mu \mathrm{g} / \mathrm{ml}$ de penicillinamine, $15 \mu \mathrm{M}$ de hypotaurina e $1 \mu \mathrm{M}$ de epinefrina. A inseminação foi realizada pela adição $20 \mu \mathrm{l}$ de sêmen, previamente selecionado pelo método de migração ascendente (swim-up), com uma concentração final de $1 \times 10^{6}$ células $/ \mathrm{mL}$. Após um período de incubação de 24 horas os oócitos/zigotos foram desnudados com auxílio mecânico (vortex), submetidos à três banhos em TCMHepes e cultivados em SOFaaci (HOLM et al., 1999).

O cultivo foi realizado a $39^{\circ} \mathrm{C}$ em estufa de cultivo com atmosfera de $5 \% \mathrm{CO}_{2}$, em $400 \mu \mathrm{l}$ de SOFaaci, sob óleo mineral. Com 48 horas de cultivo foi avaliada a taxa de clivagem, momento em que foram mantidos apenas os zigotos clivados, sendo a partir de então utilizada uma bolsa (BAG) com atmosfera de $5 \% \mathrm{CO}_{2}, 5 \% \mathrm{O}_{2}$ e $90 \% \mathrm{~N}_{2}$ para o período restante de cultivo. A taxa de blastocistos foi avaliada com 8 dias de cultivo no experimento I e com 7 dias de cultivo no experimento II e III. Os dados observados foram submetidos à análise de variância e quando necessário ao teste $\mathrm{T}$, com nível de significância de 5\%.

\section{Resultados e Discussão}

As taxas de desenvolvimento embrionário obtidas após a criopreservação de oócitos bovinos ainda são baixas e isto normalmente é atribuido às características intrinsecas destas estruturas (PARKS e RUFFINING, 1992). Tem sido demonstrado que o período de maturação exerce influência na viabilidade pós criopreservação, sendo os estágios mais tardios os que proporcionam maior viabilidade (LIM et al., 1992), muito embora $\mathrm{HOCHI}$ et al. (1998) tenham demonstrado maior viabilidade com oócitos vitrificados com 12 horas de maturação. Outros fatores como diferenças nos meios de cultivo também influenciam o posterior desenvolvimento embrionário de oócitos bovinos criopreservados (MEZZALIRA, 2001), sendo todos bem documentados. Além destes, fatores como o desnudamento parcial, também pode exercer influência, sendo todavia escassos os estudos que investigam este efeito, principalmente com oócitos criopreservados. FATHEHI et al. (2002) relatam um acentuado decréscimo nas taxas de clivagem (56\% para $25 \%$ ) de oócitos maturados submetidos ao desnudamento. Em nosso estudo, no experimento I, foi possível 
demonstrar um efeito negativo $(P<0,05)$ da remoção das células do cúmulus com a utilização de sucessivas pipetagens, que determinou a redução da taxa de blastocistos de $28,7 \%$ no controle, para $20,5 \%$ no grupo desnudado (TABELA 1). Muito embora tenha ocorrido uma queda da viabilidade, esta foi muito inferior à observada por FATHEHI et al. (2002). Entretanto, estes autores realizaram o desnudamento total dos oócitos, enquanto em nosso estudo o desnudamento foi parcial.

TABELA 1 - TAXAS DE CLIVAGEM E BLASTOCISTOS DE OÓCITOS BOVINOS SUBMETIDOS AO DESNUDAMENTO AO DESNUDAMENTO PARCIALATRAVÉS DE SUCESSIVAS PIPETAGENS.

\begin{tabular}{cccc}
\hline TRATAMENTOS & $\begin{array}{c}\text { Oócitos utilizados } \\
(\mathrm{n})\end{array}$ & $\begin{array}{c}\text { CLIVAGEM } \\
\%\end{array}$ & $\begin{array}{c}\text { BLASTOCISTOS } \\
\%\end{array}$ \\
\hline $\begin{array}{c}\text { Controle } \\
\begin{array}{c}\text { Desnudamento com } \\
\text { pipetador }\end{array}\end{array}$ & 439 & 81,3 & $28,7^{\mathrm{a}}$ \\
\hline Total & 370 & 73,5 & $20,5^{\mathrm{b}}$ \\
\hline $\mathrm{a}, \mathrm{b}$ Letras diferentes na mesma coluna indicam diferença estatística $(P<0,05)$. & 24,6
\end{tabular}

A redução da viabilidade embrionária demonstrada em função do desnudamento com sucessivas pipetagens, demonstra a necessidade de se adequar a metodologia a uma forma menos injuriosa de realizar o processo, buscando reduzir este efeito negativo. Algumas alternativas são sugeridas na literatura, como a utilização de equipamentos que associam micro-canais e micro-fluídica (ZERINGUE et al., 2002) ao possibilitarem taxas de clivagem de $90 \% \mathrm{com}$ oócitos desnudados. Entretanto, o equipamento não está disponível no mercado. GORDON (2003) relata estudo realizado na Irlanda na década de 80 , o qual sugere que oócitos submetidos a uma solução de citrato de sódio a $3 \%$ por cinco minutos com movimentos suaves, é capaz de remover as células do cumulus sem efeitos adversos. FONTES et al. (2002) avaliaram diferentes protocolos de desnudamento empregando hialuronidase ou tripsina, associadas ao vortex ou sucessivas pipetagens. Os autores observaram uma redução nas taxas de blastocistos em todos os grupos, que entretanto foi mais acentuada nos grupos submetidos ao vortex. Em nosso estudo, no experimento II empregou-se o desnudamento parcial com hialuronidase, comparando-o com o método anteriormente descrito de sucessivas pipetagens. Não houve diferença significativa entre os dois métodos de desnudamento e diferente do resultado observado no experimento I, os grupos desnudados não diferiram do grupo controle (TABELA 2). Estes resultados também diferem das observações de FONTES et al. (2002) que obtiveram uma queda acentuada da viabilidade após o desnudamento. Todavia, estes autores realizaram o desnudamento completo dos oócitos, o que pode ter determinado um maior dano às estruturas.

TABELA 2 - TAXAS DE CLIVAGEM E BLASTOCISTOS DE OÓCITOS BOVINOS SUBMETIDOS AO DESNUDAMENTO PARCIAL ATRAVÉS DE SUCESSIVAS PIPETAGENS OU UTILIZANDO HIALURONIDASE.

\begin{tabular}{cccc}
\hline TRATAMENTOS & Oócitos utilizados $(\mathrm{n})$ & $\begin{array}{c}\text { CLIVAGEM } \\
\%\end{array}$ & $\begin{array}{c}\text { BLASTOCISTOS } \\
\%\end{array}$ \\
\hline Controle & 153 & 70,7 & $25,4^{\mathrm{a}}$ \\
$\begin{array}{c}\text { Desnudamento com } \\
\text { Pipetador }\end{array}$ & 149 & 60,4 & $17,7^{\mathrm{a}}$ \\
$\begin{array}{c}\text { Desnudamento com } \\
\text { Hialuronidase }\end{array}$ & 149 & 62,4 & $21,7^{\mathrm{a}}$ \\
\hline
\end{tabular}

Letras semelhantes na mesma coluna não diferem estatísticamente $(P>0,05)$. 
Embora no segundo experimento não tenha sído possível demonstrar uma diferença estatística entre os grupos, em valores absolutos os percentuais mais elevados de blastocistos ocorreram no grupo controle $(25,4 \%)$ e no grupo desnudado com hialuronidase $(21,7 \%)$. Como a finalidade do desnudamento parcial, neste caso, é apenas viabilizar o processo de vitrificação, tornou-se oportuno a realização de um terceiro experimento para avaliar as taxas de blastocistos após a criopreservação dos oócitos, previamente submetidos aos dois métodos de desnudamento parcial. Como pode ser observado na TABELA 3, também neste experimento, após a vitrificação, não foram verificadas diferenças estatísticas nas taxas de clivagem (32,0 e 41,0\%) ou de blastocistos $(6,4$ e 8,9\%) com oócitos desnudados parcialmente com sucessivas pipetagens ou com a enzima hialuronidase, respectivamente. Novamente, em valores absolutos os percentuais mais elevados de clivagem $(41,0 \%)$ e de blastocistos $(8,9 \%)$ ocorreram no grupo desnudado com hialuronidase, em relação ao grupo com sucessivas pipetagens, que todavia não foram estatisticamente significativos. Ainda, observouse que a utilização da enzima teve maior praticidade, promovendo um desnudamento parcial mais uniforme, praticamente sem variação quanto ao número de camadas celulares entre os oócitos, diferente do verificado nos oócitos desnudados com sucessivas pipetagens, onde frequentemente alguns eram excessivamente desnudados, enquanto outros permaneciam com as células intactas.

\begin{tabular}{|c|c|c|c|}
\hline TRATAMENTOS & Oócitos utilizados (n) & $\begin{array}{c}\text { CLIVAGEM } \\
\%\end{array}$ & $\begin{array}{c}\text { BLASTOCISTOS } \\
\%\end{array}$ \\
\hline $\begin{array}{l}\text { Desnudamento com } \\
\text { pipetador }\end{array}$ & 118 & $32,0^{\mathrm{a}}$ & $6,4^{\mathrm{a}}$ \\
\hline $\begin{array}{l}\text { Desnudamento com } \\
\text { Hialuronidase }\end{array}$ & 117 & $41,0^{\mathrm{a}}$ & $8,9^{\mathrm{a}}$ \\
\hline Total / Média & 235 & 36,5 & 7,6 \\
\hline
\end{tabular}

Letras semelhantes na mesma coluna não diferem estatísticamente $(P>0,05)$.

\section{Resultados}

Os resultados observados após a vitrificação foram semelhantes aos $8,0 \%$ obtidos por SANTOS et al. (2004) com oócitos desnudados parcialmente com hialuronidase, bem como aos $7,9 \%$ obtidos por MEZZALIRA et al. (2002), com oócitos desnudados através de sucessivas pipetagens e vitrificados em OPS.

Os resultados obtidos demonstram que 0 desnudamento parcial com hialuronidase pode substituir o desnudamento com sucessivas pipetagens, produzindo maior homogeneidade e praticidade, sem prejudicar a posterior viabilidade dos oócitos na vitrificação.

Novas investigações devem ser conduzidas a fim de avaliar outras causas que ainda determinam a baixa taxa de embriões após criopreservação de oócitos bovinos maturados.

\section{Agradecimento}

Os autores agradecem aos Frigoríficos Verdi, Pamplona e Fox pela disponibilidade dos ovários e cooperação no trabalho.

\section{REFERÊNCIAS}

FATEHI, A. N.; ZEINSTRA, E.C.; KOOIJ, R.V.; COLENBRANDER, B.; BEVERS, M. M. Effect of cumulus cell removal of in vitro matured bovine oocytes prior to in vitro fertilization on subsequent cleavage rate. Theriogenology, New York, v. 57, n. 4, p. 1347-1355, 2002.

FONTES, R. S.; MATOS, L. F.; REICHENBACH, $\mathrm{H}$. $D$. Effect of different denudation procedures on in vitro fertilization of bovine oocytes and embryo development. Theriogenology, New York, v. 57, n. 1, p. 665, 2002. 
GORDON, I. In vitro fertilization. In: GORDON, I. Laboratory production of cattle embryos. 2. ed. Cambridge: CAB International, 2003. p. 176-219.

HOCHI, S.; FUJIMOTO, T.; BRAUN, J.; OGURI, N. Pregnancies following transfer of equine embryos cryopreserved by vitrification. Theriogenology, New York, v. 42, n. 3, p. 483-488, 1998.

HOLM, P.; BOOTH, P.J.; SCHMIDT, M.H.; GREVE, T.; CALLESEN, H. High bovine blastocyst development in a static in vitro production system using SOFaa medium supplemented with sodium citrate and myoinositol with or without serumproteins. Theriogenology, New York, v. 52, n. 4, p. 683-700, 1999.

LIM, J.M.; FUKUI, Y.; ONO, H. Developmental competence of bovine oocytes frozen at various maturation stages followed by in vitro maturation and fertilization. Theriogenology, New York, v. 37, n. 2, p. 351-361, 1992.

MEZZALIRA, A.; VIEIRA, A.D.; CRUZ, F.B.; BARBIERI, D.P.; DAMIANI, J.C. Vitrificação de ovócitos bovinos com a utilização de micropipetas de vidro ou palhetas estiradas. Revista de Ciências Agroveterinárias, Lajes, v. 2, p. 108-114, 2002.
MEZZALIRA, A. Criopreservação e desenvolvimento de oócitos bovines tratados com citocalasina B. Santa Maria, 2001. 64 p. Tese (Doutorado em Medicina Veterinária) - Curso de Medicina Veterinária, Universidade Federal de Santa Maria.

PARKS, J.E.; RUFFINING, N.A. Factors affecting low temperature survival of mamalian oocytes. Theriogenology, New York, v. 37, n. 1, p. 59-73, 1992.

SANTOS, R.M.; BARRETA, M.E.; MEZZALIRA, J.C.; PAULINI, F.; CRUZ, F.B.; VIEIRA, A.D.; MEZZALIRA, A. Vitrificação de ovócitos bovinos em nitrogênio líquido com atmosfera normal ou vácuo (dados parciais). In: REUNIÃO ANUAL DA SOCIEDADE BRASILEIRA DE TECNOLOGIA DE EMBRIÕES, 18., 2004, Barra Bonita. Anais... Barra Bonita, 2004. (ERRATA).

ZERINGUE, H.; WALTERS, E. M.; LEIBFRIEDRUGLEDGE, L. L.; WHEELER, M. B.; BEEBE, D.J. Development of bovine in vitro-produced embryos after cumulus cell removal with a microfluidic microchannel device. Theriogenology, New York, v. 52, n. 1, p. 533, 2002.

Recebido para publicação: 27/06/2005 Aprovado: 